\title{
THE CHOICE OF A SURVIVING SIBLING AS "SCAPEGOAT" IN SOME CASES OF MATERNAL BEREAVEMENT-A CASE REPORT
}

\author{
KAY TOOLEY*
}

THE EFFECT of the death of a child on parents and siblings has received considerable attention in the psychological literature. Cain and Cain (1964) have studied bereaved families and have described a common tendency to designate one of the other children as a replacement for the lost child. The substitute child is often and inviduously compared to his dead sibling and feels strongly that the definition of his own personality and the pattern of his life is precast by that of the deceased child. We have seen another mode of managing bereavement which also utilized one of the surviving children not as a replacement but as a scapegoat, an object for the displacement of parental; particularly maternal guilt. In these cases, the loss of a child mobilizes a strong need to fix blame on a surviving older sibling who is unconsciously felt to have caused the loss of his envied sibling. Many years after the initial trauma, the relationship between the mother and the scapegoat child is bitter and estranged, filled with mutual provocation, unconscious feelings of recrimination and an extreme of hostility and punishment.

A digression is in order, at this point, to review the meaning of the term "scapegoat"-a term use frequently from the early psychotherapeutic literature to the present, because of its descriptive power and emotional resonance. Overlapping with the use of the term as a word with wide colloquial meaning, is a recent usage to delineate a syndrome (Ackerman, 1971; Watzlawick, 1970). In this report, "scapegoat" refers to a syndrome as it began to be defined by Vogel and Bell (1968), and as described more recently in detail by Bermann (1973). In Semitic history, the scapegoat was the "guilt-bearer" laden with the sins of the tribe and driven out as a gesture of propitiation to an angry and vengeful deity. In Celtic history, the scapegoat or outcast assumed the debt of his kindred. Accountability for crimes against persons or property was equally shared by clan members but the penalty demanded could be displaced to one member and he could be driven out of communal life, isolated, excoriated but not killed. The Celtic oral tradition tells us of female rulers, druids and divinities but contains no reference to outcasts (Chadwick, 1964). Scapegoats in Semitic history came from the priest caste which was composed exclusively of males. "Guilt-bearers" in the psychological literature, as well as our sample, were of both sexes.

Later, in complex urban societies a subgroup was chosen as scapegoat, always U.S.A.

*Children's Psychiatric Hospital, The University of Michigan, Ann Arbor, Michigan 48104, Accepted manuscript received 31 January 1975 
available to receive the projections and fearful anger of the dominant group in times of social stress (Adorno et al., 1950).

In 1956, Ackerman used the term descriptively to describe a similar phenomenon within the confines of the nuclear family; one member of the family, a child, was chosen as "guilt bearer" to be punished and rejected so that other family members, relieved thus of guilt and anxiety, could function with greater psychological effectiveness.

In his detailed study of a family living under the constant threat of death of the father, Bermann (1973) describes and documents in touching detail the vivid reality of scapegoating as it was practiced by this family on one of the children. $\mathrm{He}$ enumerated conditions that dictate a family's need for a scapegoat: (1) stress of considerable duration and magnitude and (2) demonstrated efficiency and efficacy of this defensive mode as opposed to others:

"Scapegoating can enjoy general and nonsporadic use. It permits the greatest gain to all (in the family) with minimal expenditure. It resolves the problem of ego dividedness, pent-up hostilities, and experiences of self-recrimination and guilt. One can disown unwanted aspects of the self by projecting them to the victim and then righteously attack those elements in the scapegoat . . . scapegoating permits low risk, error-free discharge of group or commonly experienced tensions ... people do not have to fear one another or worry about surprises; procedures are automatic. Anger, by mutual consent, is oriented in one direction and is uncontested so that in moments of surprise, change, or frustration one need not sort out the situation"' (pp. 162-163).

Further, he suggests that the family's problems are idiosyncratic in "intensity, character and/or context" (p. 166). It is personal, private and painful, thus necessitating the choice of an insider (a family member) rather than outsiders (the medical profession). An insider also has the advantage of constant availability. The above conditions lead inevitably to the last; the candidate for the scapegoat position must be expendable. "It is assumed that he comes to symbolize a piece of someone else's harried or traumatic childhood, a piece of someone else's terrifying guilt, a piece of someone else's unconscious. ... The point is the scapegoat is denied his own existence. Expendability has another connotation, that of luxury. . . . The creation of an in-system scapegoat assumes sufficient personnel or talent elsewhere in the organization to carry out basic functions-economic, childrearing, household maintenance" (p. 169).

I would add that children carry important psychological roles in families. There might, in addition, need to be a sufficient number of other children available to carry projections of the good aspects of the parents' selves or their hopes for the future, for scapegoating to occur.

Bermann (1973) attempts to describe a general category. I will be describing a special sub-category which differs from the general in only one aspect; when these "scapegoats" were removed from the family, no "replacement candidate" was chosen. I submit that this is because the stress was intense over a significant period of time but that it is not currently operant in the family system. It happened in the past. It is however psychologically operant, revivified, between scapegoat child and mother whenever feelings of rejection and hostility are awakened in the latter. Although other children in the family may awaken such feelings in the mother, they do not, by their own feelings of guilt, link the current animosity to the past intense trauma and play out the complementary role. 
The family pathology to be described fits Bermann's (1973) criteria in all other respects -idiosyncrasy of family problem, "expendability" of the chosen child, economy and expediency of this form of group defense. The case illustration which follows was chosen not on the basis of vividness or unusualness but rather on the basis of representativeness. The circumstances and the symptomatic behavior are so similar across cases that a presentation of some of this material at a professional meeting produced a rash of phone calls from other mental health workers who "recognized" a former patient or a client family from the case description. Needless to say, they were wrong but they provided a kind of independent confirmation of the widespread, highly recognizable, only slightly varying nature of the pathological interaction to be described.

\section{Case description}

Linda Z. was 6 yr old; the second in a sibship of 5 which included 1 older and 1 younger sister and 2 younger brothers. She was brought to the hospital by a court social worker, having become a ward of the court some months earlier when a neighbor notified authorities that Linda had been locked out of her home for several hours in near zero weather in flimsy clothing. An investigation by child welfare workers confirmed this and several other instances of rather extreme punishment related by Linda, and confirmed by her parents, relatives and teachers. Following a court hearing Linda had been placed in two foster homes. The first foster mother found her to be "a lovely child" but could not keep her because of her own family's proposed move to another state. The second foster mother found her stubborn, provocative and intractable.

In the hospital, three psychometric evaluations over 3 years confirmed that Linda's I.Q. fell within the average range. Her school performance was age and grade appropriate. Her parents were high school graduates. Her father was a foreman in an industrial plant, occasionally supplementing his income with a night job in plant protection. Her mother was a housewife. Their income, standards and style of living would be classified as lower-middle-class.

A careful reconstruction of the facts in Linda's case confirmed a mother-child interaction characterized by extremes of misbehavior and defiance on the part of the child, countered by extremes of sadistic punishment on the part of the mother. Such incidents as defecating on the rug while grinning up at her mother as she entered the livingroom, shredding of siblings' clothes and bedding, prying up floor tiles after being isolated in her room for punishment, energetic defacing of wooden furniture with a scissors were some of Linda's contributions to the hostilities.

The incident which moved the neighbor to notify the juvenile authorities represented a typical Sunday of escalating warfare. It began when Linda was "bad" in church: talking loudly, moving about, poking her sisters and brothers, giggling. Mrs. Z. decreed no Sunday dinner and isolation in her room as punishment. With quiet absorption Linda scribbled with crayon on all of the bedroom walls. Her mother presented 6-yr-old Linda with water, cleanser and an ultimatum to clean it up and to stay there until it was done. Linda throws the water at her mother and laughs and refuses. The mother tells her in a fury that she doesn't deserve a nice home and a nice family, and then puts her outside "until you can say you're sorry and that you'll be good". Linda is flimsily dressed because she has destroyed her winter coat, and her parents who have little money see no point in replacing it. Linda sits and mopes prominently around the door and windows for $4 \mathrm{hr}$, informing all who pass that she is being punished. (She could be very forlorn and wistful at such times.) It never entered her head to comply with her mother's conditions for re-entering. The mother, newly furious, lets her in after sundown and receives the court investigators the next day.

During the $3 \mathrm{yr}$ Linda was in residential treatment and intensive psychotherapy her parents were also seen, but the regularity of their participation, as will be described, was highly variable. As one examines the life histories of Linda and her mother there are some indications of the cause of the warfare, the basis for their bad bargain - that one must punish and the other must be intransigent. One of Linda's younger siblings had died soon after birth as a result of a congenital defect and another had to be hospitalized for severe mental retardation. Mrs. Z. had conveyed both directly and verbally as well as indirectly that she held her specially "bad" child Linda responsible for the tragedies 
involving these infants. Linda accepted this designation of herself as murderous so matter-of-factly that it was easily possible to trace extremely provocative behavior followed by extreme punishment to the vicissitudes of the medical condition of her other siblings (Cain and Fast, 1964). When a younger brother had had to be hospitalized for symptoms that might have been serious but in fact turned out to be minor, Linda began to urinate in the cooking pans of her compulsively clean mother. In another instance which occurred during her treatment period, a lapse into extremely provocative behavior ensued after her 3-yr-old sister got the measles. Linda defecated on the livingroom rug at home and refused to go to school at the hospital. Her mother asked that Linda not come home to visit for a time because she had given her sister the measles and she didn't want the other children infected. (There was an epidemic of measles at the public school her other children attended.) Linda unquestioningly accepted the blame and later expressed great guilt and anxiety to her therapist. Her aunt had told her that measles caused mental retardation and blindness in babies and Linda sadly recalled her hospitalized retarded brother.

Linda's special significance to her mother was alluded to by Mrs. Z. herself when she filled out the initial hospital admission form. Under "Reason for Referral"' Mrs. Z. wrote: "I myself have a very strong feeling of rejection towards Linda because of the constant attention that was given her by my husband's family when she was very young through the age of 4 . This disturbed me because Rita (Linda's 1-yr-old sister) was a very little girl and was constantly pushed off into a corner or told, 'We don't like you because we didn't see you grow up', and so on. I was a very left out child myself and still am (sic). This I couldn't bear to see happening to my Rita as I know the feeling of loneliness to a great extent." Mrs. Z. consistently continued to identify Linda as her own deprived, unloveable child-self. Linda was the sibling that was fat and dark of skin and hair like her mother; the others were "fair and pretty". Linda's place in the sibship is identical to her mother's.

Linda was 15 months old when her severely retarded little brother was born. Ricky cried all the time. He grew to be a "big boy" and still couldn't walk, feed himself or talk. Linda stopped walking for a period, refused to feed herself and later on, around $3 \mathrm{yr}$ of age, relapsed into enuresis and soiling after her early and successful toilet training. She very firmly pressed her claim to the same favored treatment the baby was getting. Her destructive provocativeness and intransigence, however, occurred after the baby was institutionalized when she was 4 . Mrs. Z. describes this period as the end of the time when Linda was overindulged by her grandparents and the beginning of "proper discipline" for her.

Linda's therapy hours revealed her early resentment at the amount of time and attention her brother claimed because of his incapacity. She formulated all of the expectable theories to explain his highly enviable prolonged infancy: he was a boy, he had a penis, Linda had had one too but she had been justly deprived of it because she was such a greedy, angry girl. Ricky was "given away" when he was 3 , to Linda's considerable pleasure and much more considerable guilt. She very much felt that her oral greed was a dangerous and punishable quality. Her mother reports that beginning at age 4 and continuing to the time of referral at age 6, Linda "ate too much of everything, like you were going to take it away from her", and that then she would often vomit. This was a later reflection of her infant behavior; she was reported to have nursed greedily and then vomited. Linda's mother felt that this child had always claimed her limited resources, whether milk, food or clothing and then "wasted it". Linda saw such behavior as insurance that when she took something that was rightfully hers, it couldn't be taken away from her and given to the baby if she "chewed it up" first.

After Ricky was institutionalized, Mrs. Z. felt temporarily relieved at having the burden of her retarded child's care taken from her. But the low tolerance for stimulation noted in her psychological testing, her wish for a placid life focused on self-gratification led her rather quickly to find the other four children too much to cope with. The wish to be less encumbered mobilized old fantasies that such wishes are fulfilled, that children may be taken from her care. This fantasy induced guilt and self-hatred. Mrs. Z. typically managed such efforts by splitting them off and projecting them. When Linda was available to receive such projections, she received her mother's accusations of being hateful to her brothers and sisters with a complementary unconscious fantasy which was also historically determined. Such accusations awakened old guilt over Ricky and awakened a guilty need to be punished and extruded herself. She was highly likely to respond then to accusation with provocation. Linda's defiance would increase her mother's anger, guilt, and wish to be rid of Linda. Mrs. Z., of course, had many moments of anger at her other children but they reacted with swift 
compliance to her wishes and they lacked the complementary guilty fantasy with which Linda completed and renewed her mother's sadomasochistic cycle.

This dynamic sabotaged Linda's post-hospital adjustment. Shortly after she was returned to her home, her mother found herself pregnant and began to worry that the child she was expecting might also be damaged. Mrs. Z. didn't "discover" the pregnancy until she was five months into it. She would never have considered a therapeutic abortion in any case because of her unconscious view of herself as a dangerously rejecting mother. She had, in addition to this psychological burden, considerable discomfort and medical problems that necessitated her confinement to bed for the last few months of the pregnancy. She began to find the demands of the rest of her family an intolerable burden. Her "specially bad" child, Linda, had been returned home after $3 \mathrm{yr}$ with us an an inpatient - our best estimate at that time being that both parents and child had developed a healthy understanding of their impact on each other and had demonstrated it over a tranquil six-month period of gradually increasing contact with each other. Linda at first responded to her mother's difficult pregnancy with good will and with emergency reserves of helpfulness. She, $9 \mathrm{yr}$ old then, and her sister Rita, 10, took care of the little children, saw to the laundry and cooking-and took considerable care of their mother too. Their father helped them only occasionally since he was working at two jobs but he conveyed his huge appreciation at how well they were doing. He would plan presents and special treats to reward them for their truly extraordinary efforts. We were pleased but also apprehensive, feeling that a normal family might show considerable strain under such pressure, let alone this extremely vulnerable family.

Linda's mother had told us she was due to deliver in February; she delivered in April. Whether the discrepancy was attributable to miscalculation, purposeful misleading or whatever is still not clear to us. In those two extra months of what seemed an interminable pregnancy, the mother's fear of bearing another damaged child, further proof of her own inner evil, escalated considerably her profound unconscious wish not to be pregnant. She began to convey that she was worried about Linda's reaction to the new baby. She told everyone who would listen, including Linda, that she was afraid Linda would want to hurt the baby, indeed might even kill the baby. Linda's reaction to this, with our support and interpretation, was confined to a very depressed withdrawal from the family's interaction. Mrs. Z. refused to have any contact with us during this period and during the crucial three months following the baby's birth. Mr. Z. brought Linda to see her therapist and continued rather sporadically in casework himself.

We hoped that Mrs. Z.'s projections would cease when the baby was born. After she delivered a normal infant in April, she suffered a moderately severe post-partum depression. She withdrew to her bedroom, her card games, and her "girl friends", leaving Linda and her sister with one more little charge to care for. Linda began to exhibit her old refusal to help or to comply with disciplinary measures. Her mother quickly slipped into the old role of scapegoating Linda. Linda appeared for her therapy appointments with bruises on her face again, non-verbal, and in deep despair. She would spend most of her therapy hours with her head down on her arms, crying silently. Through all of this period her school performance was adequate and her peer relationships age appropriate. The teacher was surprised and angered by Mrs. Z.'s phone calls in which she would detail Linda's wickedness so that the teacher would not be "taken in" by her.

Our efforts to intervene with Linda's father and mother were unsuccessful in every permutation and combination of personality and location. We received triumphant and furious reports from Mrs. $Z$. that Linda had torn Rita's winter coat to shreds, had "attacked" Larry, had purposely broken dishes, had kicked her in the stomach. There had been no behavior remotely resembling this for almost 2 yr. Mr. Z. had withdrawn from the family, was drinking too much too often; and was away for days at a time. Within a few weeks, we moved to take Linda from her home when she began storing knives under her mattress and announcing to her mother that "one morning you'll wake up and find all your children killed". When Linda was removed, the father and mother were easily reconciled and the mother was able to resume adequate functioning as mother and housekeeper. Linda was placed in a group home and from the day of admission to this writing her functioning has been described as "good to excellent".

Linda's mother had never permitted an examination of her feeling about the loss of her infants through death and through institutionalization. Any effort to touch upon this subject led to an avoidance of treatment. Mrs. Z. had, however, allowed herself to perceive sympathetically evidence 
of Linda's sense of guilt and worthlessness. We felt that when Mrs. Z. could endure the recognition of guilt and low self-esteem in herself, she would not split it off and project it. Her ability to tolerate the psychological pain involved in this recognition allowed her to sympathize with Linda's feelings of guilt and worthlessness. Since we had hypothesized that splitting and projection was a key mechanism in the mother-daughter estrangement, we felt that when we had evidence that empathy had replaced projection, we had grounds for being optimistic about returning Linda home. We could not foresee either the pregnancy or its awesome effects.

\section{DISCUSSION}

A common hypothesis is frequently made to explain the special "scapegoat child": that he or she preserves family peace by accepting the guilt for unacceptable impulses for the whole family; that such a scapegoat serves an important emotional function in a family that uses externalization and displacement as typical ego defenses. When the scapegoat is removed or somehow escapes this role, the family chooses another member to perform this necessary psychological function. This was not the case with Linda's family nor with other similar families. These families were typical of our clinic population as a whole. They were lower-middle to middle class by occupation, education and income and sturdily middle class in value orientation, sharing a conscious commitment to the Protestant ethic and to middle-class standards for child rearing, cleanliness and general propriety. They were, as is also modal for our clinic population, caucasian, steadily employed, two-parent families. Five of the children were treated as inpatients, one as an outpatient, and one via shortterm parent guidance-the last fortunately referred when the scapegoat arrangement was in statu nascendi. Three of the inpatient children were court referrals as child abuse cases; two have been expelled early in their school careers as unmanageable behavior problems, having generalized their home behavior to school. The single outpatient was the youngest, 5-yr-old and already displaying signs of unmanageability in kindergarten.

The families functioned much better when the special child was extruded and did not choose a replacement to serve as guilt bearer. The virulence of the relationship was highly specific-confined to one parent and one child. This suggests rather strongly that the very negative mother-child relationship so evident to all observers is not so much a contemporary guilt-avoidance arrangement which the family, particularly the mother needs so that she can function. Rather the reasons for the special relationship seem to be rooted historically in the mother's childhood together with very traumatic experiences when she later becomes a mother. Mrs. Z. was a "very left out" child herself. Another mother in her own childhood had lost a younger sibling because of serious congenital defects and had a history of severe beatings, finally being extruded from the household at $14 \mathrm{yr}$. Another mother in this group had been sent to live with grandparents at age 9 . She remembers no explanation that she could present to us. Her siblings remained at home. She mentions vaguely that they were poor and that they probably hadn't enough food for her. In summary, there is objective reason for thinking that these women had reason for feeling extremely rejected in their own families of origin.

The sense of being inadequate and unloveable is vividly reawakened and magnified by a confluence of coincidences at a particularly vulnerable point in the development of an identity as wife and mother. The coincidences involved on the 
one hand narcissistic pain or shame over the actual or symbolic loss of a child, and on the other hand the availability of another child who through an accident of coloring, age, place in the sibship, or style of relating evokes memory of a "bad" child self.

"Loss of child" in these cases involved death, but also involved separation by other means. In the case of Linda, a severely retarded child was institutionalized at age 3 . In another case, the mother was declared immoral and unfit in a court procedure that used her advanced pregnancy, carrying our future patient, as visible proof of her sexual delinquencies. Her two older children were taken from her custody and placed for adoption under circumstances that provide a shocking (though fortunately dated) example of the intrusion of puritan righteousness into the legal system with a consequent infringement of parental rights. The charge of immorality hinged on the fact that there was doubt about the legality of the mother's marriage and divorce some years earlier. She was, however, young, poor and vulnerable to community scorn and saw our patient as the proof of her "immorality" and the living present cause of the loss of her other children.

Two mothers in this sample had lost children in crib deaths and one of a congenital disease diagnosed soon after birth. The prognosis in the latter case was that the child would die within months. The mother hoped the doctors were wrong and was plunged into grief when the infant died-on the 4th birthday of her daughter who became our patient through court referral for child abuse $4 \mathrm{yr}$ later.

It is true that the mothers in this sample were particularly vulnerable to shame and guilt because of the circumstances of the loss. Other authors have described the grief and narcissistic shame that afflicts mothers who give birth to congenitally damaged children "the mourning of the child that might have been" (Olshansky, 1962). There is also a tendency in these mothers to consider themselves as deficient in their capacity for successful procreative femaleness. The birth defect seems to reflect on their sexual and human worth and their moral goodness. In the case of crib deaths also, the unpredictability and the mysterious suddenness leaves the parents psychologically groping for an "explanation" and extremely vulnerable to guilt feelings. Although the bereavements suffered by the mothers in this sample have an unusually high shame and guilt potential, we are not prepared to infer that it is causal in the scapegoat arrangement described.

There is also evidence from work with these women that they suffer from very low self-esteem and a tendency to split off from their self-perceptions aspects which they consider bad, and to project these unfavored aspects of the self to the scapegoat child. It seems that the combination of this personality configuration with the coincidence of a narcissistically damaging loss is necessary to produce the extremes of family pathology described. The projection of the bad self by the mother perhaps serves the function of forestalling a psychotic break or a severe depression. It is an emergency solution.

When the emergency grief situation is over, the relationship with the selected child does not resume its pre-emergency character, however, The psychic arrangement endures long after the situational need for it has disappeared. All of the scapegoat children were resigned to accept guilt for a range of misfortunes that extended from a burnt dinner to a measles epidemic. The mothers saw them as excessively 
greedy and demanding from infancy; two of them having a historical and contemporary pattern of eating large amounts of food and vomiting. The rising crescendo of parent-child warfare characterized by stereotyped provocation and rigid sadistic punishment was extremely similar across cases.

The child has a capacity for splitting objects also. Aspects of the self are displayed differentially to those in the environment. The result is a strong split in those comprising the treatment milieu; the "good objects" seeing the lonely and frightened rejected child and the "bad objects" seeing an extremely demanding, provocative, manipulative, over-indulged and under-controlled brat-one who makes them feel ready to do anything to assert their control over her in an eerie replay of the original warfare with the mother. Both the mothers and the treatment staff must be prevented from surrendering to the unconscious demands for punishment which these children present during the course of treatment.

Linda's mother was never able to discuss with her therapist the feelings aroused by the birth of her retarded child, through the years of care to his eventual removal. Any effort to touch upon it led to cancelled appointments and an avoidance of the hospital that would last for several weeks. This was not the case with some of the other mothers. They could and would struggle to convey the pain and guilt experienced at the time when they lost their children. The fathers, who seem like bewildered and helpless bystanders when the mothers refuse or avoid the subject, are able to help when the mothers show readiness to mourn and work through their grief. They support, sympathize and recollect. Being less narcissistically and in: timately involved than the mothers, they also produce, indignantly, "old wives" tales" which neighbors and relatives have related to their wives to explain sudden infant death or congenital defect, e.g. infant blindness is caused by a latent venereal disease, kidney malformations are caused by maternal smoking during pregnancy or mental retardation is a recrudescense of a strain of idiocy and degeneracy that infests the maternal family. (It is interesting to note the denigrating mythology of women obvious here. None of the "explanations" we hear implicate the male in his child's deficiency.) The working through of the loss experience and the mutual comforting and sharing between husband and wife seemed to foreshadow a new willingness to reconsider the needs and problems of the scapegoat child; the mothers no longer felt so desperately guilty, accused and convicted.

The cases treated are not hopeless, only difficult. Mothers who react to loss as these mothers did are typically not introspective, verbal or self-observing. This does not imply that they have little capacity for psychological pain. The widely underestimated function of shame in the avoidance of therapeutic confrontation explains to a great degree their resistance to treatment. When a pathological mother-child $\{$ relationship has had years to become chronic and malignant, residential treatment seems the-only viable option. However, if obstetricians and pediatricians were to be made aware of this distortion of the grieving process, successful interventions might well be possible earlier in the process. For example, one set of parents in this sample were referred for psychiatric consultation a few months after the crib death of their infant son (personal communication with David Youngs, M.D., Psychiatric Consultant, Department of Obstetrics and Gynecology, The University of Michigan Medical Center). The parental interviews were characterized by considerable 
bitter recrimination on the part of the father who accused the mother variously of not wanting the baby, of not caring for him as well as she might have and, most ominously, of "wrapping him too tight" and causing him to smother. The mother turned aside his attacks by saying that no one could say what caused the baby's death, no one except their 4-yr-old daughter; she was alone in the room with him the night it happened and she certainly wasn't overly fond of him. This mode of managing guilt and grief had already become well rooted in the mother-daughter interaction and was successfully discouraged by counseling. If it had not been, we feel confident that this little girl would have posed a problem similar to that of the other children in this group.

Experiences in group work with the parents of mentally retarded infants have taught us how much such parents can comfort each other and how much they can do to drain off the sense of shame and to mitigate the sense of an utterly personal and disgraceful tragedy. Preventive interventions after such a bereavement, whether in the form of parent groups or conjoint counseling, might well forestall the sad estrangement of bitter parent-child warfare not only in the current family but in future generations.

\section{SUMMARY}

This paper presents a description of a pathological variation of the mourning process in mothers who have suffered a narcissistically damaging psychological or actual loss of a child. A surviving sibling chosen as a displacement object for the mother's sense of guilt and self-hatred. The parent-child estrangement continues for years after the trauma with an extremity and severity that often necessitates court intervention. A case illustration is presented and a concluding suggestion that counseling by available professionals at the time of the bereavement would be both economical and effective in forestalling this variety of pathological family scapegoating.

\section{REFERENCES}

Ackerman, N. W. (1958) The Psychodynamics of Family Life. Basic Books, New York.

Ackerman, N. W. (1971) Prejudicial scapegoating and neutralizing forces in the family group. In Theory and Practice of Family Psychiatry (Edited by Howelns, J. G.). Brunner Mazel, New York.

Adorno, T. W., Frenkel-Brunswik, E., Levinson, D. J. and Sanford, R. N. (1950) The Authoritarian Personality. Harper \& Row, New York.

Bermann, E. (1973) Scapegoat: The Impact of Death-Fear on an American Family. University of Michigan Press, Ann Arbor, Michigan.

Cain, A. C. and Cain, B. S. (1964) On replacing a child. J. Am. Acad. Child Psychiat. 3, 433-456.

CAIn, A. C., FAst, I. and ERICKson, M. (1964) Children's disturbed reactions to the death of a sibling. Am. J. Orthopsychiat. 34, 741-752.

Chadwick, N. (1964) Celtic Britain, Vol. 34, Ancient People and Places (Series Edited by Glyn, D.). Praeger, New York.

Olshansky, S. (1962) Chronic sorrow: A response to having a mentally defective child. Social Casework 43, 191-193.

Vogel, E. F. and BeLl, N. (1968) The emotionally disturbed child as the family scapegoat. In A Modern Introduction to the Family (Edited by BeLl, N. and Voges, E.). New York Press, New York.

Watzlawick, P., Beaven, J., Sikorski, L. and Mecia, B. (1970) Protection and scapegoating in pathological families. Family Process 9, 27-39.

Youngs, David (1971) Personal communication. 
This document is a scanned copy of a printed document. No warranty is given about the accuracy of the copy. Users should refer to the original published version of the material. 